\title{
REVISED Dispersion is essential in crop residue application
}

\section{[version 2; peer review: awaiting peer review]}

Previously titled: Dispersion has a large effect (Cohen's $d$ ) on crop yield in crop residue application

\section{Masato Oda}

Crop, Livestock and Environment Division, Japan International Research Center for Agricultural Sciences, Tsukuba, Japan

V2 First published: 21 Nov 2018, 7:1831

https://doi.org/10.12688/f1000research.16748.1

Latest published: 18 Feb 2020, 7:1831

https://doi.org/10.12688/f1000research.16748.2

\section{Abstract}

Background: Crop residue application can maintain soil fertility and sustain agriculture. However, the effects of residue application are unstable because of variable weather conditions and the residual effects of crop residue application. Furthermore, residue application often reduces crop yields. Therefore, I tried to clarify effective residue application factors in an environment which was has stable weather conditions and low residual effects.

Methods: Majuro atoll, a coral sand atoll near the equator, was selected for the experiment site because of its stable weather and low residual effect of coral sand. A factorial design experiment using sweet corn was conducted based on the following four factors: fungi propagation before application, cutting residue into pieces, dispersion (or accumulation) of applied residue, and placement (on the surface or incorporation) with an equal amount of crop residue. The effects of each factors on the corn yields were evaluated using Cohen's power analysis.

Results: The dispersion showed the largest effect (1.2 in Cohen's), which exceeded the effect of incorporation (0.7). The interaction of dispersion and incorporation showed a huge effect (4.9) on corn yield. Discussion: The effect of dispersion was not positive but it avoided the negative effects of residue clustering. Because, the toxicity of the plant residue and generation of toxic substances by anaerobic decomposition are widely known. Anaerobic decomposition occurs inside the residue clusters. However, dispersion reduced the toxicity by adsorption in soil and avoiding anaerobic decomposition. Furthermore, incorporation showed an interaction effect, but surface placement did not.

Conclusion: The dispersion of crop residue enhanced the positive effect of crop residue incorporation by avoiding the toxicity from crop residue. This finding adds a new viewpoint for the controversy between conventional and conservation agriculture

\section{Open Peer Review}

Approval Status AWAITING PEER REVIEW

Any reports and responses or comments on the article can be found at the end of the article. 
Keywords

Conservation agriculture, Crop residue, Green manure, Marshall Islands, Organic matter application, Soil degradation, Anaerobic decomposition

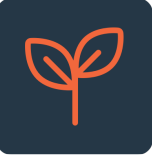

This article is included in the Agriculture, Food

and Nutrition gateway.

Corresponding author: Masato Oda (oda.masato@affrc.go.jp)

Author roles: Oda M: Conceptualization, Data Curation, Formal Analysis, Investigation, Methodology, Resources, Writing - Original Draft Preparation

Competing interests: No competing interests were disclosed.

Grant information: The author(s) declared that no grants were involved in supporting this work.

Copyright: @ 2020 Oda M. This is an open access article distributed under the terms of the Creative Commons Attribution License, which permits unrestricted use, distribution, and reproduction in any medium, provided the original work is properly cited.

How to cite this article: Oda M. Dispersion is essential in crop residue application [version 2; peer review: awaiting peer review] F1000Research 2020, 7:1831 https://doi.org/10.12688/f1000research.16748.2

First published: 21 Nov 2018, 7:1831 https://doi.org/10.12688/f1000research.16748.1 


\section{REVISED Amendments from Version 1}

1) The title was changed clearly showing the contents.

2) Readability was improved in the abstract.

3) A sentence was added to the end of the introduction section for clarifying the methodology.

4) Figure 2 is corrected using DW data of which stated in the document.

5) The discussion section became compact and clear.

Any further responses from the reviewers can be found at the end of the article

\section{Introduction}

Soil degradation is a major constraint on food security (Gomiero, 2016; Lal, 2015), and the intervention points for reversing soil degradation are soil erosion and depletion of soil organic matter (Karlen \& Rice, 2015). Conservation agriculture or green manure approaches are developing against this backdrop and emphasize the importance of retaining crop residue (Cherr et al., 2006; Pittelkow et al., 2015a); however, they have not yielded satisfactory results. For example, long-term trials of conservation agriculture show no particular interactions among factors such as tillage, mulch, rotation, soil texture and rainfall (Pittelkow et al., 2015b).

The main problem with crop residue application is that the decomposition of the residue can have both positive and negative effects on crop production (Kumar \& Goh, 1999). Nitrogen benefits and nitrogen recovery from residues show that they have considerable potential (Kumar \& Goh, 1999). However, microorganisms produce toxic substances during the decomposition of plant residue. Microorganisms metabolize these substances in aerobic soils. Nonetheless, the phytotoxic leachates of some decomposing cover crop residues have adverse effects on crops even under aerobic conditions (Bhowmik \& Doll, 1982; Jessop \& Stewart, 1983; Kimber, 1973a; Kimber, 1973b; Lynch, 1977; Lynch, 1978; Stirzaker \& Bunn, 1996).

The application method of crop residue is a major factor in the success of the method, although the effects of organic matter application also differ by the quantity, conditions and timing (Chen et al., 2014; Tian et al., 2007). Both particle size and placement of the applied material affect the residue breakdown rate and the mineralization/immobilization process (Kumar \& Goh, 1999). However, environmental factors have strong interactions with residue decomposition (Kumar \& Goh, 1999). Finding effective crop residue application methods is difficult without stable weather and with the inability to control for no residual effects of organic matter, even with a focus on the application method.

The aim of this study was to clarify the most effective crop residue application method. Although, there are many factors concerning residue management (Kumar \& Goh, 1999), I examined four factors (fungi propagation, cutting, dispersion and incorporation) from the viewpoint of farmers applicability. Experiments were conducted in low fertility and high microorganism's activity environment. That enabled clear observing the effect of applied residue on crop yields.

\section{Methods}

Site description and conditions

Majuro Atoll, the capital of the Republic of the Marshall Islands, is located in the Pacific Ocean near the equator. The maximum and minimum monthly average temperatures are 29.4 to $30.2^{\circ} \mathrm{C}$ and 24.7 to $25.0^{\circ} \mathrm{C}$, respectively. The average monthly precipitation is 169 to $356 \mathrm{~mm}$, and the average annual precipitation is 3, $365 \mathrm{~mm}$ (CLIMATE-DATA.ORG). Coral sand, the soil of Majuro atoll, has relatively high organic matter levels in top soil due to refractory organic matter (organic carbon of $46.9 \mathrm{~g} \mathrm{~kg}^{-1}$ at $0-15 \mathrm{~cm}$ and $10.8 \mathrm{~g} \mathrm{~kg}^{-1}$ at $15-45 \mathrm{~cm}$ ) (Deenik \& Yost, 2006), and high percolation rates $\left(1.4-3.5 \times 10^{-3} \mathrm{~m} \mathrm{~s}^{-1}\right)$ (Hunt \& Peterson, 1980). Thus, the climate is stable, the soil has high permeability with no waterlogging, and frequent rainfall keeps the soil moisture close to field capacity, so applied organic matter is almost decomposed in the crop period. It is known that the residual effect of organic resources is small for sandy soils in a warm and humid climate (Chivenge et al., 2011).

The experimental field was located at Laura Farm (78"34"N, $171^{\circ} 2^{\prime \prime} 9$ "E), which belongs to the Ministry of Resources and Development. The field size was $12.5 \times 7.2 \mathrm{~m}$. The plot size was $1.2 \times 6.0 \mathrm{~m}$, and the experimental field consisted of two sets of six plots. The government forbids the use of synthetic fertilizer and chemicals on this atoll in order to protect the underground aquifer; therefore, farmers use copra cake as fertilizer. Soil water-soluble $\mathrm{NO}_{3}-\mathrm{N}$ (0-5 cm layer; 1:2.5 soil:water extraction) was $4 \mu \mathrm{g} \mathrm{g} \mathrm{soil}{ }^{-1}$, as assessed by a nitrate ion meter (LAQUAtwin B-742, Horiba, Tokyo). No significant residual effect has been found in this field, although corn had been cropped three crops without fertilizer nor any chemicals from November 26, 2013 to July 28, 2014 (see raw data (Oda, 2018)).

\section{Materials and crop management}

Corn residue to be used as the material for the experiment was harvested on July 28, 2014, just after the harvest of the previous crop of corn in the experimental field. The residue was divided into 12 bundles of the same fresh weights of $4.7 \mathrm{Mg} \mathrm{ha}^{-1}$ (2.1 $\mathrm{Mg} \mathrm{ha}^{-1}$ in dry weight) and applied to the plots by different methods (described later). Corn (Zea mays L.) was planted in two rows at $0.5 \mathrm{~m}$ row spacing at a population of 3.3 plants $\mathrm{m}^{-2}$ on August 4, 2014, and harvested on October 21, 2014 (78 days after seeding). Irrigation, fertilizer and chemical applications were not performed. Hand weeding was performed 2 and 5 weeks after seeding and the weed residue was left on the soil surface of the plot.

\section{Treatments}

An $\mathrm{L}_{12}$ orthogonal array design was used in the experiment (Taguchi, 1986). This design was used to ensure robust experimental results under a wide range of conditions. Only the main effects were seen in the experiments, and all the factor levels had six replications. The 12 experiments consisted of four factors (fungi propagation, cutting, dispersion and incorporation) that were randomly assigned to the experimental plots (Table 1). The 
Table 1. Experimental matrix for $\mathrm{L}_{12}$ orthogonal array. The 12 experiments consisted of four factors (fungi propagation, cutting, dispersion and incorporation), which were randomly assigned to the experimental plots.

\begin{tabular}{|c|c|c|c|c|}
\hline No. & $\begin{array}{c}\text { Fungi } \\
\text { propagation }\end{array}$ & Cutting & Dispersion & Incorporation \\
\hline 1 & $\bigcirc$ & & $\bigcirc$ & \\
\hline 2 & & & & $\bigcirc$ \\
\hline 3 & $\bigcirc$ & $\bigcirc$ & & \\
\hline 4 & 0 & & & 0 \\
\hline 5 & & & $\bigcirc$ & $\bigcirc$ \\
\hline 6 & $\bigcirc$ & $\bigcirc$ & 0 & $\bigcirc$ \\
\hline 7 & & 0 & $\bigcirc$ & \\
\hline 8 & 0 & & & \\
\hline 9 & & 0 & & $\bigcirc$ \\
\hline 10 & & 0 & & \\
\hline 11 & $\bigcirc$ & $\bigcirc$ & $\bigcirc$ & $\bigcirc$ \\
\hline 12 & & & 0 & \\
\hline
\end{tabular}

four different treatments were established as follows. In the fungi propagation factor, the residue was stored in a compost house for 7 days until propagating fungi, and the remainder of the residue stored beside the field. For the cutting factor, the residue was cut into $10 \mathrm{~cm}$ pieces. For the dispersion factor, the residue was scattered evenly on the plots, and for the non-dispersion, the residue was placed on the center line of the plot in a swath approximately $30 \mathrm{~cm}$ wide. For the incorporation factor, I removed approximately $5 \mathrm{~cm}$ thickness of soil of the plots, then placed the residue, and covered the residue with the soil (Figure 1).

\section{Validation of the linearity of input and output}

Strong linearity must be found between returned residue quantity and the yield if the adopted factors have a robust performance (Taguchi, 1986). For validation purposes, I returned the crop residues into the same plot using the combination of the two most effective factors (dispersion and incorporation). The plot effect can confound the yields in this plot design since the quantity (0.4-2.0 Mg ha $\mathrm{ha}^{-1}$ in dry weight) of applied residues was proportional to the preceding yield in each plot. However, this conflict was considered to be small because the plot effect was very small in this field (see raw data (Oda, 2018)) and the residual effect of corn was small. I seeded corn on October 28, 2014 and harvested it on January 9, 2015 (73 days after seeding).

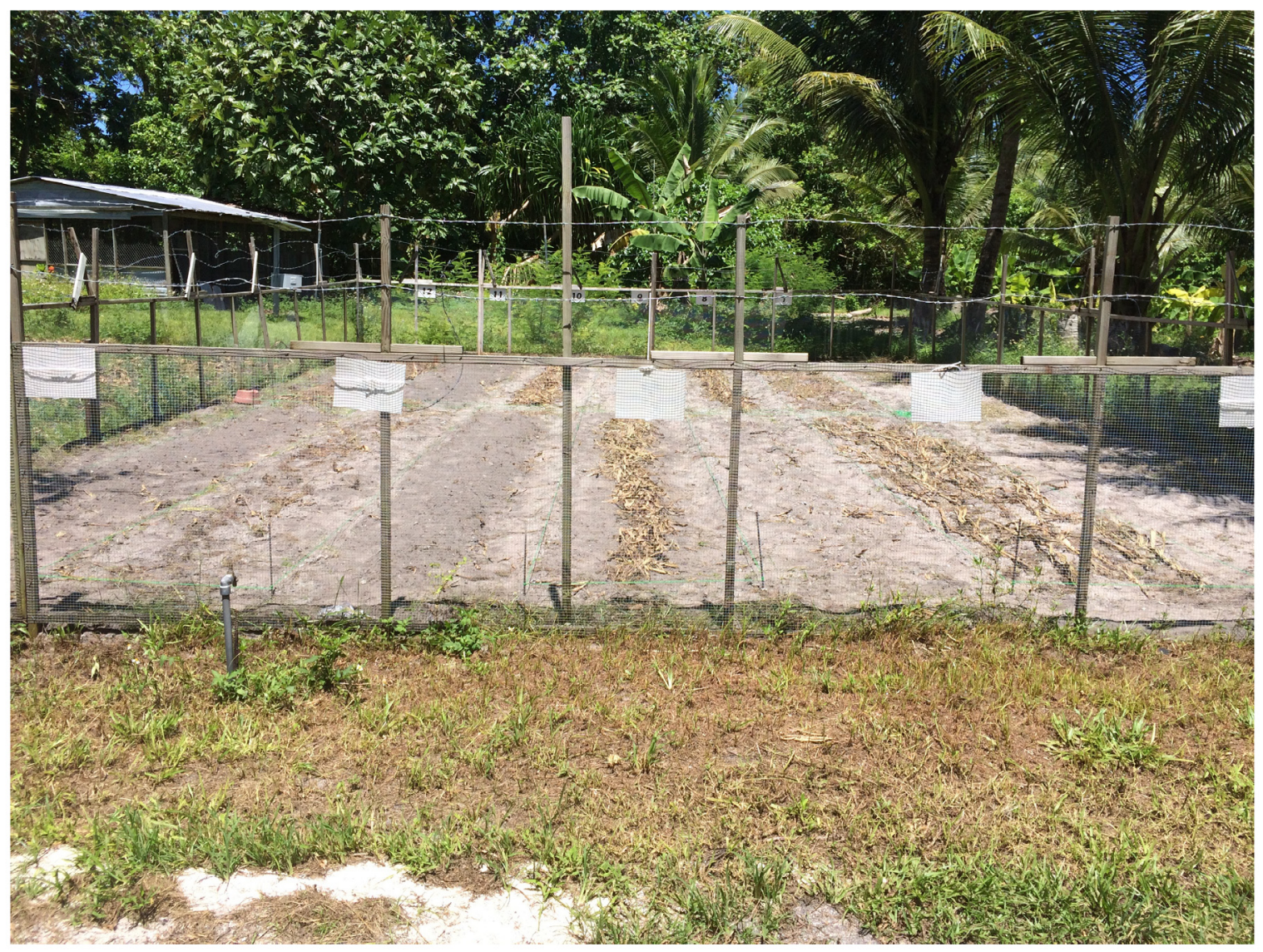

Figure 1. Photograph of the condition of the experimental field. The 12 experiments consisted of four factors (fungi propagation, cutting, dispersion and incorporation), which were randomly assigned to the experimental plots. 
Determination of yields and statistical analyses

I got precipitation data from the automatic weather station at the Laura Farm. I weighed the fresh weight of the whole crop and the kernels in each plot and checked the kernel/whole ratio was stable $\left(R^{2}=0.9983\right)$. The aboveground dry matter (DM) was calculated by multiplying the fresh weight to an aboveground $\mathrm{DM} /$ fresh-kernel-weight ratio (2.79) of an existing study (Miura \& Watanabe, 2002). The aboveground residue DM was calculated by multiplying the DM/fresh ratio (0.46) of air-dried residue sample. Statistical power analysis was conducted using the effect size of Cohen's $d$ (Cohen, 1992) by the MS Excel 2016.

$$
\mathrm{d}=\frac{M_{1}-M_{2}}{\sqrt{\frac{S D_{1}^{2}+S D_{2}^{2}}{2}}}
$$

\section{d: Effect size, M: Mean, SD: Standard deviation}

A significance is affected by the sample size; however, Cohen's $d$ is not affected by sample sizes and can evaluate the true effect. The $p$ values were calculated with an unpaired, one-sided, unequal variances $t$-test. I evaluated the linearity of the input and the output using the coefficient of determination $\left(R^{2}\right)$ in a simple linear regression

\section{Results}

\section{Climate conditions}

There were no irregular climate conditions during the experimental periods. The number of precipitation days for each 78-day and 73-day crop period were 58 and 54 days, respectively, and total precipitation was 1111 and $542 \mathrm{~mm}$, respectively.

\section{Effect size of the application methods}

Table 2 shows the results of the power analyses. The effect sizes of Cohen's $d<0.2,0.5,0.8$ and 1.2, and $d>2.0$ correspond to small, medium, large, very large and huge, respectively (Cohen, 1992; Sawilowsky, 2009).

Dispersion had a larger effect ( $p=0.045$, Cohen's $d=1.2$ ) than incorporation ( $p=0.223$, Cohen's $d=0.7$ ). Fungi propagation and cutting had no effect (Cohen's $d=0.0-0.1$ ). I calculated the effects of dispersion and incorporation, assuming the effects of cutting and fungi propagation to be negligible. The interaction was huge ( $p=0.005$, Cohen's $d=4.9$ ), while the main effect of dispersion (Cohen's $d=0.3$ ) and incorporation (Cohen's $\mathrm{d}=-0.2$ ) were medium and small in effect size, respectively (Table 3 ).

\section{Linearity of input and output}

Under the combination of dispersion and incorporation, input (the quantity of applied residue) was proportional to the output (harvested aboveground biomass) (Figure 2; $R^{2}=0.8963$ ).

\section{Discussion}

Dispersion had a very large effect on corn yield. The yield was influenced by the huge effect of the interaction of dispersion and incorporation. The dispersion of crop residue
Table 2. Effect size of crop residue application method factors on crop

yield. The same amount of crop residue was applied to plots by different methods (fungi propagation, cutting, dispersion and incorporation).

\begin{tabular}{|l|c|c|}
\hline Factor & Cohen's d & P \\
\hline Fungi propagation & 0.1 & 0.455 \\
\hline Cutting & 0.0 & 0.477 \\
\hline Dispersion & 1.2 & 0.045 \\
\hline Incorporation & 0.7 & 0.223 \\
\hline
\end{tabular}

$P$ values: one-sided, unpaired, unequal distribution t-test $(n=6)$.

Table 3. Estimated effect size of dispersion and incorporating. The same amount of crop residue was applied to plots by different methods (fungi propagation, cutting, dispersion and incorporation) The effect sizes on corn yields were calculated neglecting the un-effective factors in Table 2. P values: one-sided, unpaired, unequal distribution t-test $(n=3)$.

\begin{tabular}{|c|c|c|c|}
\hline \multicolumn{2}{|c|}{ Factor } & Cohen's d & $p$ \\
\hline Dispersion & Incorporation & & \\
\hline+ & + & 4.9 & 0.005 \\
\hline+ & - & 0.3 & 0.392 \\
\hline- & + & -0.2 & 0.420 \\
\hline
\end{tabular}

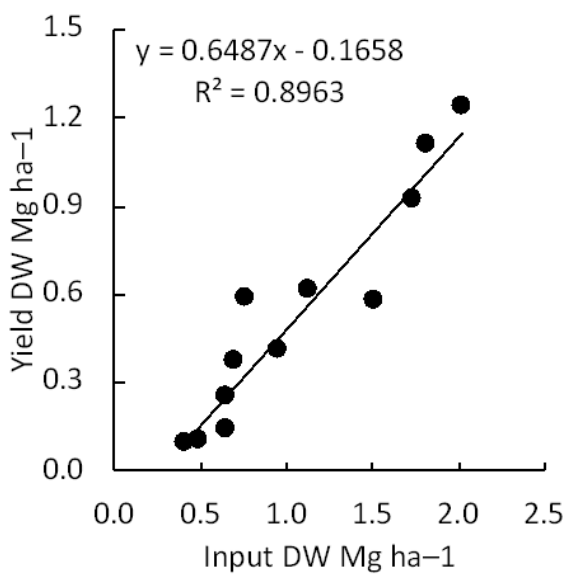

Figure 2. Biomass output based on the quantity of corn residue input. Crop residues were returned into the same plot using the combination of the two most effective factors (dispersion and incorporation).

application having a large effect on yield is probably a new finding.

A positive effect for dispersion is surprising, given that dispersion typically increases nutrient loss. Intuitively, application of crop residues away from plants should be less effective 
(Stone et al., 2000). The results of this study will be reasonable if dispersion avoids the negative effect of residue clustering. This is because crop residue retained at the surface or incorporated into the soil may produce phytotoxic allelochemicals (Chung \& Miller, 1995; Weston, 1996). In addition, Martin et al. (1990) reported that corn stover is itself phytotoxic. The combination of the toxicity produced by the decomposition of residue by bacteria, fungi and extract of residue results in different levels of toxicity.

For the aspect of adsorption, dispersion increases the adsorption of phytotoxic substances in soil. Adsorption is the most important soil factor controlling the fate of chemicals in the environment because it controls the chemical concentrations present in the soil solution, which is a physiological phenomenon that follows the Freundlich equation (Vidal \& Bauman, 1997). This means that dispersion has a stable effect on avoiding phytotoxicity. We should pay closer attention to the dispersion of residue incorporation because tillage merely buries the residue (Staricka et al., 1991).

Conversely, the positive effect of incorporating crop residue on yield is because of the nutrient addition (Kumar \& Goh, 1999), especially given that this experiment was conducted without fertilizer addition. Matching the amount and timing of nitrogen release with crop nitrogen demand is a key component of crop production (Robertson, 1997).

The combination of dispersion and incorporation brings a proportional yield increase to applied residue under nonfertilized conditions. In this case, the yield will reflect the nutrient applied by the residue. Furthermore, incorporation had an interactive effect, but surface placement did not. Residue incorporation, rather than surface placement, may enhance biological nitrogen fixation by reducing the inorganic $\mathrm{N}$ in soil
(Kumar \& Goh, 1999); however, further study is needed in this area.

\section{Conclusion}

A stable climate with a low residual effect of soil can reveal a stable result for crop residue management. Cohen's power analysis showed the dispersion of crop residue had a very large effect on corn yield, and the effect arose from the interaction with incorporation. Dispersion will avoid phytotoxicity from anaerobic conditions inside residue clusters and clarify the positive effect of crop residue incorporation. This finding adding a new viewpoint for the controversy between conventional and conservation agriculture.

\section{Ethics statement}

This study was conducted with the permissions from the local government.

\section{Data availability}

Figshare: Majuro Supplemental data, https://doi.org/10.6084/ m9.figshare.6668129.v1 (Oda, 2018). Data from Experiments 3 and 4 includes data that supports the results of this article.

Data are available under the terms of the Creative Commons Zero "No rights reserved" data waiver (CC0 1.0 Public domain dedication).

\section{Acknowledgements}

I wish to thank the Ministry of Resources and Development for their cooperation, especially Mr. Jabukja Aikne and the Taiwan Technical Mission for providing seeds and tractor service. I also wish to express my deepest thanks to Mr. Susumu Yoshimura for supporting these experiments.
Bhowmik PC, Doll JD: Corn and Soybean Response to Allelopathic Effects of Weed and Crop Residues1. Agron J. 1982; 74(4): 601-606. Publisher Full Text

Chen B, Liu E, Tian Q, et al:: Soil nitrogen dynamics and crop residues. A review. Agron Sustainable Dev. 2014; 34(2): 429-442.

Publisher Full Text

Cherr CM, Scholberg JM, McSorley R, et al:: Green manure approaches to crop production: A synthesis. Agron J. 2006; 98(2): 302-319.

Publisher Full Text

Chivenge $\mathrm{P}$, Vanlauwe B, Six J: Does the combined application of organic and mineral nutrient sources influence maize productivity? A meta-analysis. Plant Soil. 2011; 342(1-2): 1-30

Publisher Full Text

Chung IM, Miller DA: Allelopathic Influence of Nine Forage Grass Extracts on Germination and Seedling Growth of Alfalfa. Agron J. 1995; 87(4): 767-772. Publisher Full Text

Cohen J: A power primer. Psychol Bull. 1992; 112(1): 155-159.

PubMed Abstract | Publisher Full Text

Deenik JL, Yost RS: Chemical properties of atoll soils in the Marshall Islands and constraints to crop production. Geoderma. 2006; 136(3-4): 666-681. Publisher Full Text

Gomiero T: Soil Degradation, Land Scarcity and Food Security: Reviewing a
Complex Challenge. Sustainability. 2016; 8(3): 281

Publisher Full Text

Hunt CD Jr, Peterson FL: WRRCTR No.126 Groundwater Resources of Kwajalein Island, Marshall Islands. 1980.

Reference Source

Jessop RS, Stewart LW: Effects of crop residues, soil type and temperature on emergence and early growth of wheat. Plant Soil. 1983; 74(1): 101-109. Publisher Full Text

Karlen DL, Rice CW: Soil Degradation: Will Humankind Ever Learn?

Sustainability. 2015; 7(9): 12490-12501.

Publisher Full Text

Kimber RWL: PHYTOTOXICITY FROM PLANT RESIDUES II . THE EFFECT OF TIME OF ROTTING OF STRAW FROM SOME GRASSES AND LEGUMES ON THE GROWTH OF WHEAT SEEDLINGS The influence of water extracts of rotted wheat straw on the growth of wheat and oat plants was described in rotted wheat straw on the growth of whe
Part. Plant Soil. 1973a; 38(2): 347-361.

Reference Source

Kimber RWL: PHYTOTOXICITY FROM PLANT RESIDUES: III. THE RELATIVE EFFECT OF TOXINS AND NITROGEN IMMOBILIZATION ON THE GERMINATION AND GROWTH OF WHEAT. Plant Soil. 1973b; 38(3): 543-555.

Publisher Full Text

Kumar K, Goh KM: Crop Residues and Management Practices: Effects on Soil 
Quality, Soil Nitrogen Dynamics, Crop Yield, and Nitrogen Recovery. Adv Agron. 1999; 68: 197-319.

Publisher Full Text

Lal R: Restoring Soil Quality to Mitigate Soil Degradation. Sustainability. 2015; 7(5): 5875-5895.

Publisher Full Text

Lynch JM: Phytotoxicity of acetic acid produced in the anaerobic decomposition of wheat straw. J Appl Bacteriol. 1977; 42(1): 81-87.

PubMed Abstract | Publisher Full Text

Lynch JM: Production and phytotoxicity of acetic acid in anaerobic soils containing plant residues. Soil Biol Biochem. 1978; 10(2): 131-135.

Publisher Full Text

Martin VL, McCoy EL, Dick WA: Allelopathy of Crop Residues Influences Corn Seed Germination and Early Growth. Agron J. 1990; 82(3): 555-560.

Publisher Full Text

Miura S, Watanabe Y: Growth and Yield of Sweet Corn with Legume Living

Mulches(Agronomy). Jpn J Crop Sci. 2002; 71(1): 36-42.

Publisher Full Text

Oda M: Majuro Supplemental data.xlsx. figshare. Dataset. 2018.

http://www.doi.org/10.6084/m9.figshare.6668129.v1

Pittelkow CM, Liang X, Linquist BA, et al.: Productivity limits and potentials of the principles of conservation agriculture. Nature. 2015a; 517(7534): 365-368. PubMed Abstract | Publisher Full Text

Pittelkow CM, Linquist BA, Lundy ME, et al.: When does no-till yield more? A global meta-analysis. Field Crops Res. 2015b; 183: 156-168.

Publisher Full Text

Robertson GP: Nitrogen use efficiency in row-crop agriculture: crop nitrogen use and soil nitrogen loss. Ecology in agriculture. Academic Press, New York.
1997; 347-365.

Publisher Full Text

Sawilowsky SS: New Effect Size Rules of Thumb. J Mod Appl Stat Methods. 2009; 8(2): 597-599.

Publisher Full Text

Staricka JA, Allmaras RR, Nelson WW: Spatial Variation of Crop Residue Incorporated by Tillage. Soil Sci Soc Am J. 1991; 55(6): 1668-1674.

Publisher Full Text

Stirzaker RJ, Bunn DG: Phytotoxicity of Ryegrass and Clover Cover Crops, and a Lucerne Alley Crop for No-till Vegetable Production. Biol Agric Hortic. 1996;

13(1): 83-101.

Publisher Full Text

Stone EL, Migvar L, Robison WL: Growing Plants on Atoll Soils. 2000

Publisher Full Text

Taguchi G: Introduction to quality engineering: designing quality into products and processes. 1986.

Reference Source

Tian G, Badejo MA, Okoh Al, et al:: Effects of residue quality and climate on plant residue decomposition and nutrient release along the transect from humid forest to Sahel of West Africa. Biogeochemistry. 2007; 86(2):

217-229.

Publisher Full Text

Vidal RA, Bauman TT: Fate of allelochemicals in the soil. Ciência Rural. 1997; 27(2): 351-357. Publisher Full Text

Weston LA: Utilization of Allelopathy for Weed Management in

Agroecosystems. Agron J. 1996; 88(6): 860-866.

Publisher Full Text 
The benefits of publishing with F1000Research:

- Your article is published within days, with no editorial bias

- You can publish traditional articles, null/negative results, case reports, data notes and more

- The peer review process is transparent and collaborative

- Your article is indexed in PubMed after passing peer review

- Dedicated customer support at every stage

For pre-submission enquiries, contact research@f1000.com 